\title{
Handset Antenna Design For Mobile Communication System
}

\author{
Anis Suliman Ali $^{1}$, Sholeh Hadi Pramono ${ }^{2}$, M. Sarosa ${ }^{3}$ \\ ${ }^{1}$ (Electrical Department, Brawijaya University, Indonesia) \\ ${ }^{2}$ (Electrical Department, Brawijaya University, Indonesia) \\ ${ }^{3}$ (Computer Science, State Polytechnic, Indonesia)
}

\begin{abstract}
Monopole slot antenna is suitable for handset applications due to its simple planar structure. Besides that, it is compact, low cost, low profile and easy to manufacture. It also has wide bandwidth and omnidiractional charatriesticts. The monopole antenna is obtained by cutting monopole slot at the edge of the ground plane of the antenna. These slots operate as the radiating elements of the antenna. The objective of the project is to design a multiband planar monopole slot antenna. This design tool used is the Zeland IE3D software. The proposed antenna consists of two slots cut at the edge of a $100 \times 40 \mathrm{~mm}$ ground plan. The antenna occupies an area of $50 \times 40 \mathrm{~mm}$. A microstrip feedline is used to feed the antenna. The proposed antenna can operate in GSM 850, GSM900, GSM1800, and GSM1900. It has two wide bands centered at $862 M H Z$ and $1768 \mathrm{MHZ}$. The frequency range of the lower band is from $811 \mathrm{MHZ}$ to $981 \mathrm{MHZ}$. The frequency range upper band is from 1572MHZ to 2503MHZ. The antenna has high return loss with 2:1 VSWR. The bandwidth percentage of the lower band is $18.97 \%$ whereas the upper band is $45.68 \%$ at -10dB return loss. The efficacy of the antenna is greater than $70 \%$.
\end{abstract}

Keywords: Monopole Slot Antenna, Two Wide Band, Omnidirectional.

\section{INTRODUCTION}

Handset antenna is an essential device for the mobile communication system. It is a critical element that can either enhance or constrain system performance ${ }^{[1]}$. The development cellular handsets have experienced rapid growth and evolution ever since it was first introduced in the 1980s.

In the past, the mobile communication devices are heavy, large and require high power to operate. The first type of antennas recognized for mobile communication devices were wire antennas such as monopole antennas ${ }^{[2]}$. These antennas can achieve high gains, are simple to design and have wide bandwidth. The design of handset antennas received much attention along with the development of cellular handsets. Nowadays, handsets have become more attractive, lighter and smaller. Hence, internal or builtin antennas are more preferred than conventional wire antennas which are external to the cellular handset. In the 1990s, handsets that can operate in two cellular frequency bands have become the minimum requirement in Europe ${ }^{[3]}$.

Multiband handsets allow users to use the same cellular phone in multiple networks that has different operating frequency band. In the current mobile communications system, the handset is no longer a voiceonly mobile unit. For example, the third generation mobile handsets that operate in the IMT-2000 frequency band offer high-end service capabilities like video-on demand high speed multimedia data services and mobile Internet access. As the functions of the handsets expand, multi-antenna integration in one handset is required ${ }^{[4]}$.

\section{DESIGN OF ANTENNA}

The proposed antenna design as shown in Figure 1. is printed on a $100 \mathrm{x} 40 \mathrm{~mm}^{2}$ system circuit board of the handset. This dimension of system circuit board is generally used in handsets. The material chosen for the antenna is a FR4 substrate with thickness $0.8 \mathrm{~mm}$. The dielectric permittivity of the substrate is 4.6 and loss tangent is 0.0245 . The antenna is fed electromagnetically by a micro strip transmission line. The parameters are shown in Table 1.

It is found that a monopole slot antenna can be obtained by cutting slots at the edge of the antenna's ground plane. Therefore, the proposed antenna consists of two monopole slots cut at the edge of the ground plane to form a multiband antenna. These monopole slots acts as resonant structures in the antenna. The two slots are labelled Slot 1 and Slot 2. Slot 1 has the length of $30 \mathrm{~mm}$ and width of $7.5 \mathrm{~mm}$. This slot controls the excitation of the antenna's lower band to cover GSM 850 and GSM 900. Slot 2 has the length of $32.5 \mathrm{~mm}$ and width of $1.5 \mathrm{~mm}$. Slot 2 controls the excitation of the antenna's upper band to cover GSM 1800, GSM 1900, IMT 2000 and 2.4 GHz. WLAN. The two slots are place in the orientation as shown in Figure 2.Because the antenna was found to be able to generate wide bandwidths at this orientation. 


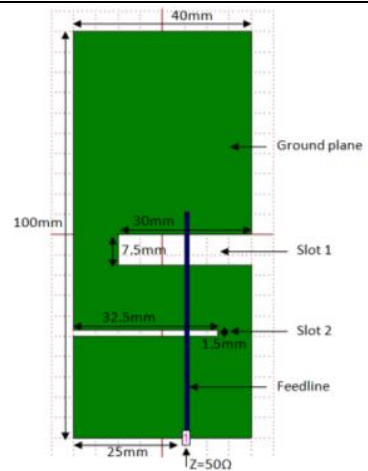

Fig 1. Dimension of presented antenna

Table1. Design parameters

\begin{tabular}{|l|l|}
\hline Substrate & FR4 \\
\hline Thickness & $0.8 \mathrm{~mm}$ \\
\hline Dielectric Permittivity & 4.6 \\
\hline Loss Tangent & 0.0245 \\
\hline Ground Plane & $100 \times 40 \mathrm{~mm}^{2}$ \\
\hline Slot 1 & $7.5 \times 30 \mathrm{~mm}^{2}$ \\
\hline Slot 2 & $1.5 \times 32.5 \mathrm{~mm}^{2}$ \\
\hline Feeding Method & Microstrip Feedline \\
\hline
\end{tabular}

Figure1. shown Proposed antenna design. Proposed antenna design is using 2 Slot pada groundplane to obtain dualBand.The microstrip feed line is printed on the backside of the antenna. It is located at $25 \mathrm{~mm}$ away from the edge of the ground plane. The width of the feed line is $1.0 \mathrm{~mm}$ and the length is $55.5 \mathrm{~mm}$. The microstrip feed line is fed at the bottom of the antenna's ground plane. This is because it was found that the antenna can operate in the frequency bands specified in the design specifications in Table 1. when the microstrip feed line is connected to the coaxial connector at this is position. The input impedance of $50 \mathrm{ohm}$ is fed $\mathrm{to}$ the coaxial connector.

\section{SIMULATION}

Computer-aided design (CAD) tool is an essential requirement in antenna designing. It is used to model antennas and predict how they will perform. If the simulation results are good, then the antenna is constructed and tested. The IE3D electromagnetic simulator is used to model the proposed antenna in this thesis. The IE3D has many functions and is widely used to model antennas and high frequency circuits. IE3D is a very accurate fullwave electromagnetic solver because not much assumption is involved. The numerical technique used in this software is the method of moments (Mom).

The first step to model an antenna using IE3D is to launch the Zeland Program Manager. Then, open the MGRID layout editor window. MGRID is used to create the antenna structure in IE3D. Before creating the structure, the basic parameters of the antenna are defined in the Basic Parameters window. These parameters include the dielectric constant, loss tangent and thickness of the substrate layers. The type of metallic strip used is also defined. Then the meshing frequency and cells per wavelength are set. In MGRID, an antenna structure is described as a set of polygons. Hence, the shape of a polygon is drawn based on the antenna structure. After defining the ports of the antenna, the simulation process is started. If the simulation results are good, the antenna design is successful.

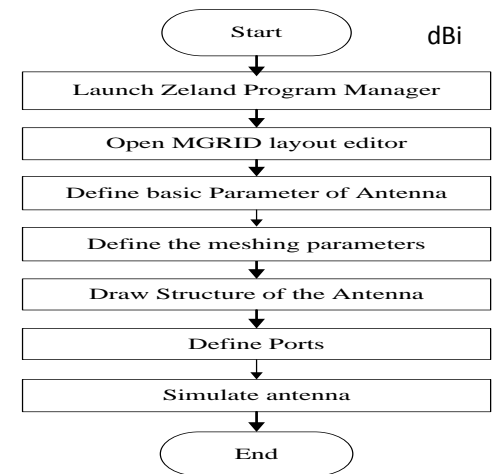

Fig 2. Flow chart of simulation 
IV. SIMULATION RESULT

The results that are presented and discussed include the return loss, voltage standing wave ratio, gain and $3 \mathrm{D}$ radiation pattern of the antenna. The proposed antenna was modeled using finite ground plane using IE3D.

\section{Return Loss}

Return loss is the difference between transmitted and reflected power in a system. It is usually expressed in decibels. An antenna with a more negative return loss value is better. Figure 3 . shows the return loss graph of the antenna. The antenna generates two wide band centered at $0.896 \mathrm{GHz}$ and $2.038 \mathrm{GHz}$. The VWSR of 2:1 with return loss of $-10 \mathrm{~dB}$ is generally used for handset antennas. At the return loss of $-10 \mathrm{~dB}$, the frequency range of the lower band is from $0.811 \mathrm{GHz}$ to $0.981 \mathrm{GHz}$. The resonance occurs at $0.862 \mathrm{GHz}$ with the return loss of $21.71 \mathrm{~dB}$. The lower band has the bandwidth of $170 \mathrm{MHz}$ covering the GSM 850 and GSM 900 operation. For the upper band, the frequency range is from $1.572 \mathrm{GHz}$ to $2.503 \mathrm{GHz}$ covering GSM $1800 \mathrm{GSM}$ 1900,. A large bandwidth of $931 \mathrm{MHz}$ formed by two resonances is obtained. The dual resonance behavior is caused by the microstrip feed line. The microstrip feed line function as a virtual short circuit across Slot 2 . At the upper band, the first resonance observed is at $1.768 \mathrm{GHz}$ with the return loss of $-22.93 \mathrm{~dB}$. The additional resonance that is generated at a frequency slightly higher than the first resonance is not so obvious.

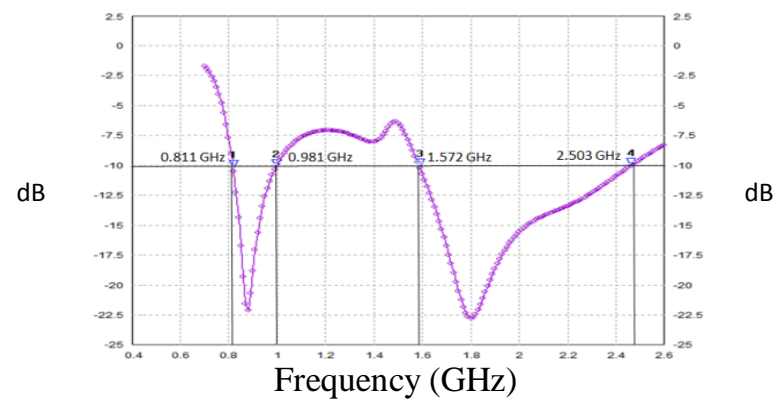

Fig 3. Return Loss graph

\section{Voltage Standing Wave Ratio (VSWR)}

Voltage Standing Wave Ratio is defined as the ratio of voltage maximum to voltage minimum on standing wave along the line caused by mismatch. It indicates whether the antenna is well match. VSWR 2:1 is generally used for handset antenna design. Figure 8. shows Voltage Standing Wave Ratio graphs for the antenna. The VSWR for the lower band varies from 1.99 to 1.94. For the upper band, the VSWR varies from 1.92 to 1.93 .

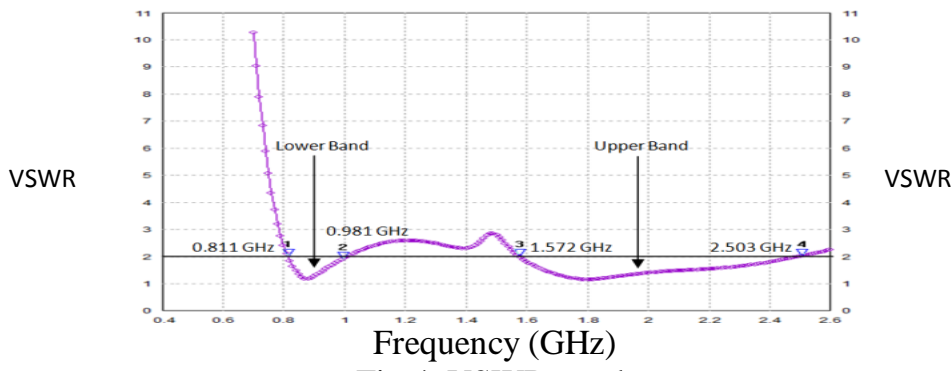

Fig 4. VSWR graph

\section{Gain}

Antenna gain indicates how much of input power is concentrated in a particular direction. It is defined as the radiation intensity in a specific direction to the radiation intensity that would be obtained if the power accepted by the antenna were radiated isotropic ally.

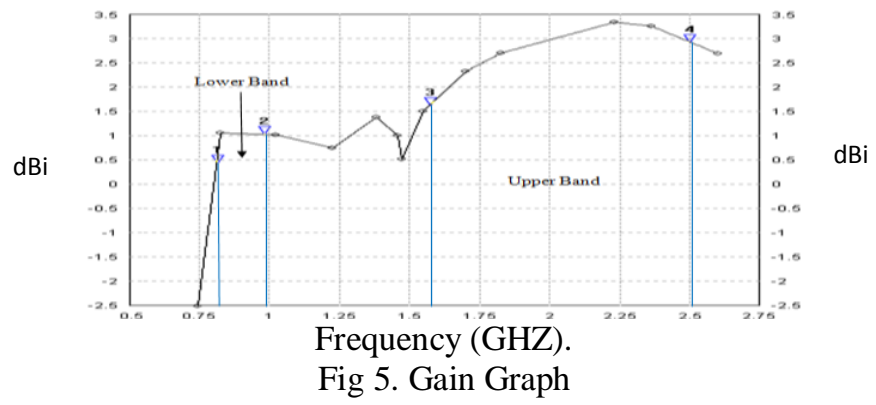


Figure5. shows gain graph of the antenna. It is desirable to obtain antenna gain that is greater than $\mathrm{O}$ $\mathrm{dBi}$. For the lower band, the antenna gain is from $0.84 \mathrm{dBi}$ to $1.13 \mathrm{dBi}$. The antenna gain for the upper band varies from $1.69 \mathrm{dBi}$ to $3.03 \mathrm{dBi}$.

\section{3D Radiation Pattern}

Figure 6. shows the $3 \mathrm{D}$ radiation pattern for lower band taken at $0.862 \mathrm{GHz}$ and the upper band taken at $1.768 \mathrm{GHz}$. The 3D radiation patterns illustrate that the antenna is omnidirectional more clearly.

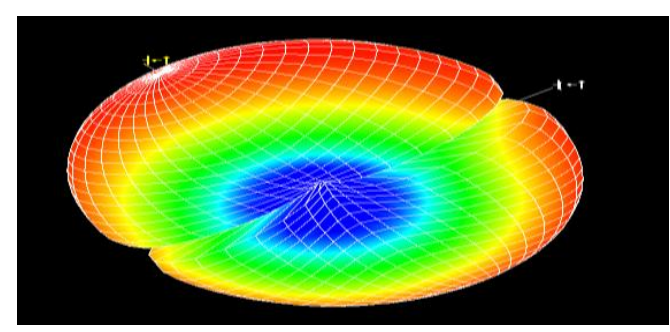

(a)

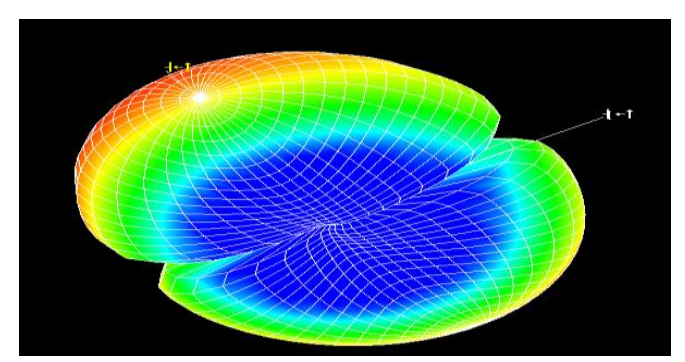

(b)

Fig 6. 3D Radiation Pattern taken at (a) $0.862 \mathrm{GHz}$ and (b) $1.768 \mathrm{GHz}$

\section{RESULT AND DISCUSSION}

The process of making the proposed antenna was carried out by using conventional method named etching process that has several stages. (1) The pattern of radiator was printed on a PCB, (2) the copper outside of the pattern was removed by a specific liquid, (3) the pattern was coated by a tin silver plate by using $\mathrm{Ag} \mathrm{NO}_{3}$ liquid, after constructing, and the complete presented antenna is shown in the Figure7.

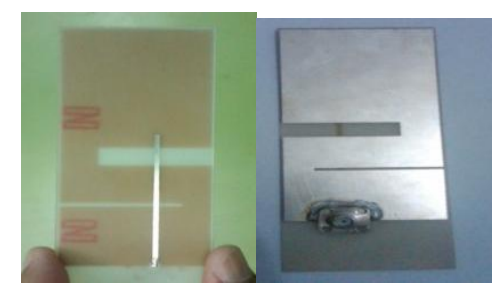

Fig 7. Shown Fabricated Antenna Had Been Throught Etching Procces.

\section{Return Loss Measurement}

RL parameter shows how much energy reflected by the antenna, therefore it can be said that RL represents the levels of matching between the antenna and the source impedances. If there is no reflected power, it means that they are matched each other and the antenna's impedance equals source's impedance. RL parameter can be measured by using a RF spectrum analyzer or a network analyzer. The value of $S_{11}$ allowed usually is $-10 \mathrm{~dB}$ that means the reflected power to be $10 \%$.

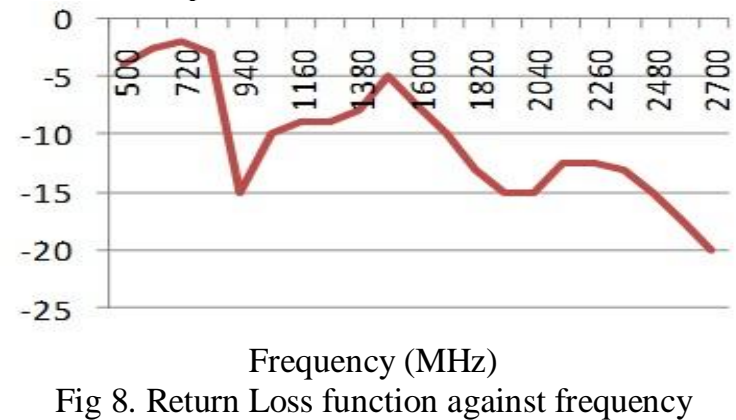




\section{Gain Measurement}

The aim of gain measurement is to know the gain of the AUT in $\mathrm{dB}_{\mathrm{d}}$ or $\mathrm{dB}_{\mathrm{i}}$. Reference antenna used in this measurement is a dipole antenna that theoretically has gain of $2.15 \mathrm{dBi}$.

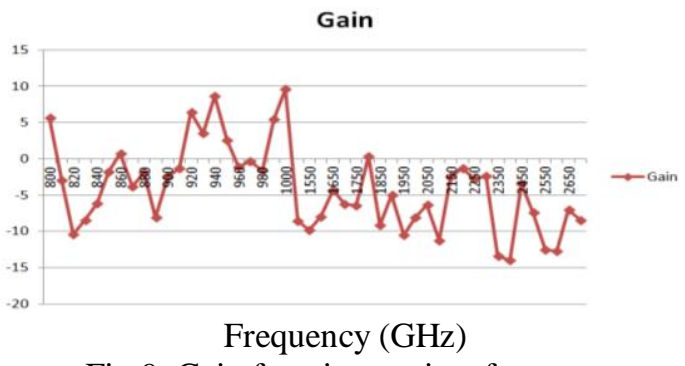

Fig 9. Gain function against frquency

\section{Radiation Pattern Measurement}

The aims of radiation pattern measurement are (1) to understand directional characteristic and half power beam width antenna, (2) to draw polar diagram of radiation pattern of AUT.

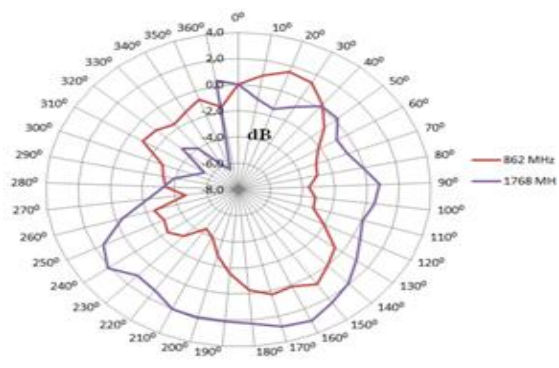

Fig 10. Radiation pattern of under test

\section{Antenna Polarization Measurement}

The purpose of this measurement is to obtain the polarization of the antenna. Polarization of the antenna refers to the direction of electric field toward ground when it is propagating.

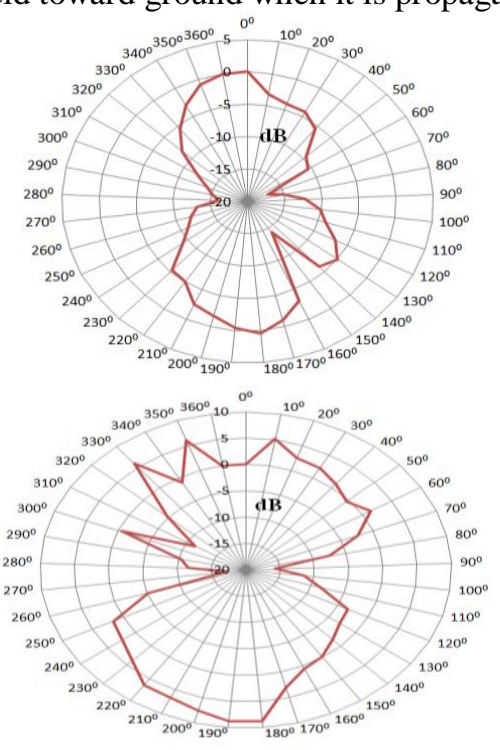

Fig 11. Antenna Polarization Measurements (a) $862 \mathrm{MHz}$ (b) $1768 \mathrm{MHz}$

Figure 11. shows Polarization for the antenna. In the Frequency of $862 \mathrm{MHz}(\mathrm{a})$ the number of maximum power is $0.4(-43.7 \mathrm{dBm})$ and the number of minimum power is-17( $-61.6 \mathrm{dBm})$, In the Frequency of $1768 \mathrm{MHz}(\mathrm{b})$ the number of maximum power is $8.9(-51.6 \mathrm{dBm})$ and the number of minimum power is $-17.2(-$ $77.7 \mathrm{dBm})$. This antenna has linear polarization. 


\section{Conclusion}

Based on the design of the antenna, antenna manufacture, antenna test and measurement, and analysis of antenna parameters, it can be concluded as follows:

1. The type of antenna designed is printed monopole slot antenna. Printed monopole slot antenna is a promising candidate to be integrated in handsets. This is because it is compact, low profile, low cost and easy to manufacture. It's simple planar structure also makes it suitable to be integrated in handsets

2. The handset antenna proposed in this thesis can operate in four frequency bands covering the GSM 850, GSM 900, GSM 1800, and GSM 1900. This antenna occupies a small space of $40 \mathrm{~mm} \times 100 \mathrm{~mm}$ and the thickness of this antenna is $0.8 \mathrm{~mm}$. it also has high return loss and efficiency. This antenna has fulfilled the design specifications. It is suitable for application in handsets used in the mobile communication system.

3. In the designed Antenna Slot 1 controls the excitation of the antenna's lower band and Slot 2 controls the excitation of the antenna's upper band.

4. The results of polarization measurements show that the microstrip antenna has been designed to have linear polarization.

\section{REFERENCES}

[1] Deng, Heng\&Feng, Zhenghe.2007. A triple-band compact monopole antenna for mobile handsets. IEEE Antennas and Propagation Sosiety International Symposium, :2069-2072.

[2] Geyi, W., Rao, Q., Ali, S. \& Wang, D. 2008. Handset Antenna Design: Practice and Theory. Progress In Electronic Research 80: 123160.

[3] Huang, Yi \& Boyle, K. 2008.Antennas: From Theory to Practice. Singapore: John Wiley \& Sons Ltd.

[4] Mohamed Sanad\&Noha Hassan. 2009. A multi-band antenna configuration for MIMO WiMax in Multi-Standard Multifunction Handsets. Mobile WiMAXSymposium, IEEE: 195-200. 